\title{
Attenuated typhoid vaccine Salmonella typhi Ty21a: fingerprinting and quality control
}

\author{
Alison J. McKenna, Jane A. Bygraves, Martin C. J. Maiden \\ and Ian M. Feavers
}

Division of Bacteriology, National Institute for Biological Standards and Control, Blanche Lane, South Mimms, Potters Bar, Hertfordshire EN6 3QG, UK Author for correspondence: Ian M. Feavers. Tel: +44 1707 654753. Fax: + 441707646730.
e-mail: ifeavers @ computing.nibsc.ac.uk

Live attenuated vaccines, developed with molecular genetical techniques, require new approaches for their quality control. To develop novel quality control tests that enhanced and extended existing procedures, the attenuated vaccine strain Salmonella typhi Ty21a and its parent strain Ty2 were characterized by pulsed-field gel electrophoresis (PFGE) and direct nucleotide sequence analysis. Mutant and parent strains were distinguished using fingerprints generated by the resolution on PFGE of chromosomal DNA digested with each of the enzymes Sfi, Spel or Xbal. These fingerprints were stable through multiple in vitro passages of the vaccine strain and were identical from one batch of vaccine to another. It was also possible to distinguish between the mutant and parent strains by direct nucleotide sequence analysis of the galE gene. This analysis identified two base changes in the gene from strain Ty21a: a single base deletion causing a frameshift that would result in a truncated gene product, accounting for the galE phenotype; and a transition that eliminated an A/ul restriction site. The consequent change in the Alul fingerprint of the galE gene in strain Ty21a provided a rapid, PCRbased alternative to the use of differential media or biochemical assays for the identification of the vaccine strain.

Keywords: Salmonella typhi Ty21a, pulsed-field gel electrophoresis, galE gene, nucleotide sequence, live vaccine

\section{INTRODUCTION}

For many years inactivated whole cell vaccines have been available for prophylaxis against typhoid fever. These require invasive procedures for immunization and repeated booster doses and are well known for causing unpleasant reactions upon immunization (Ashcroft $e t$ al., 1964; Yugoslav Typhoid Commission, 1964; Polish Typhoid Committee, 1966). The discovery that virulent strains of Salmonella typhi were attenuated by the introduction of genetic lesions into genes that encode products required for bacterial growth in vivo (Germanier \& Furer, 1975; Dougan et al., 1987; Chatfield et al., 1989; Hone et al., 1991) led to the development of live, genetically attenuated, typhoid vaccines that established self-limiting immunizing infections. These vaccines had the following advantages: (i) they could be administered

Abbreviation: PFGE, pulsed-field gel electrophoresis.

The EMBL accession number for the sequence reported in this paper is X83927. orally; (ii) they did not produce severe reactions in the vaccinee; (iii) they promoted both local and systemic antibody and cellular immune responses; and (iv) they could be used to deliver antigens from other pathogens to the immune system (Clements \& El-Morshidy, 1984; Chatfield et al., 1989, 1992; Cardenas \& Clements, 1992).

Typhoid vaccine based on $S$. typhi strain Ty21a was the first live attenuated enteric vaccine to be licensed in many industrialized countries, primarily for the immunization of travellers to typhoid endemic areas (Forrest, 1991). The Ty21a strain was derived from the virulent $S$. typhi strain Ty2 by successive rounds of NTG mutagenesis followed by screening for a stable mutation in the galE gene, which encodes UDPgalactose 4-epimerase (GalE) (Germanier \& Furer, 1975). Attenuation of Salmonella strains by galE mutations was at that time attributed to their inability to synthesize a complete lipopolysaccharide except under conditions that resulted in galactose-induced lysis (Germanier \& Furer, 1983). Strains without a complete lipopolysaccharide were believed to be more susceptible to phagocytosis and therefore less able to survive in vivo. 
During the development of the Ty21a vaccine, no attempt was made to place the galE mutation in a strain isogenic with strain Ty2, consequently $\mathrm{Ty} 21 \mathrm{a}$ has various mutations in other genes including those affecting: (i) $\mathrm{Vi}$ antigen biosynthesis; (ii) isoleucine-valine metabolism; (iii) $\mathrm{H}_{2} \mathrm{~S}$ production; and (iv) growth rate (Germanier \& Furer, 1975, 1983; Hone et al., 1988). Experiments designed to investigate the effect of galE alone on the attenuation of $S$. typhi showed that otherwise isogenic galE mutants of Ty2 were virulent in human volunteers, demonstrating that galE by itself was not the attenuating lesion (Hone et al., 1988).

Strain Ty21a vaccines have proved to be safe (Gilman et al., 1977; Wahdan et al., 1982; Germanier \& Furer, 1983; Levine et al., 1987; Black et al., 1990), although their protective efficacy has varied considerably in field trials, probably because of vaccine stability and differences in formulation, vaccination schedule and incidence of infection in the trial population (Hirschel et al., 1985; Forrest, 1991; Forrest et al., 1991; Murphy et al., 1991; Simanjuntak et al., 1991). Strain Ty21a has also been proposed as a vector for the oral delivery of heterologous antigens (Formal et al., 1981; Clements \& El-Morshidy, 1984; Chatfield et al., 1989).

The development of quality control tests for vaccines based on Ty21a is hampered by the absence of information on its attenuating mutation(s), the lack of reliable in vitro tests and the inadequacy of animal models in predicting the safety and efficacy of typhoid vaccines for man (Germanier \& Furer, 1983). Consequently, quality control of these vaccines depends largely upon monitoring the manufacturing process and confirming that the bacterial strain in a given batch is identical to that which was shown to be safe in clinical trials. Molecular genetics provides novel approaches to these problems. The present work describes the application of two molecular techniques to the characterization of the vaccine strain Ty21a and its parent strain Ty2. Pulsed-field gel electrophoresis (PFGE) fingerprinting (Schwartz \& Cantor, 1984; Carle et al., 1986; Bohm \& Karch, 1992), exploiting restriction endonucleases that cut the chromosome infrequently, permitted the rapid and detailed comparative analysis of the chromosomes of the parent and mutant strains. This approach had potential for confirming the identity and genetical stability of $S$. typhi $\mathrm{Ty} 21 \mathrm{a}$ in different batches of vaccine preparation. Direct PCR-based nucleotide sequence analysis permitted the comparison of galE genes from strains $\mathrm{Ty} 2$ and Ty21a with the sequence previously determined for the Salmonella typhimurium LT2 galE gene (Houng et al., 1990). Direct nucleotide sequence analysis, although rapid, was not suitable for routine testing, so the resulting data were used to devise a simple test to distinguish Ty2 and Ty21a based on the restriction analysis of the PCR-amplified galE gene.

\section{METHODS}

Bacterial strains and culture conditions. Cultures of the wildtype strain $S$. typhi Ty2, the mutant Ty21a, and batches of vaccine were provided by the Swiss Serum and Vaccine Institute (Berne). The bacterial strains used in this study were cultured in brain heart infusion (BHI; Oxoid) broth or on BHI agar at $37^{\circ} \mathrm{C}$ unless otherwise stated.

PFGE. This was carried out essentially as described elsewhere (Bygraves \& Maiden, 1992). The confluent growth from one agar plate of $S$. typhi grown overnight on BHI agar was scraped into $3 \mathrm{ml} \mathrm{TE}$ buffer (10 mM Tris/HCl, pH 8.0;1 mM EDTA). An even suspension of the cells was made which was then mixed with an equal volume of melted $1.0 \%(\mathrm{w} / \mathrm{v})$ Sea-Plaque agarose (FMC Bioproducts) in TE at $37^{\circ} \mathrm{C}$ and directly dispensed into several pre-cooled plastic moulds $(0.1 \mathrm{ml}$ capacity; PharmaciaLKB) and allowed to set on ice. The plugs were removed from the moulds and incubated overnight at $55^{\circ} \mathrm{C}$ in SET $(1 \%$, w/v, Sarkosyl; $10 \mathrm{mM}$ Tris/HCl, pH 9.5; 0.5 M EDTA) with pronase $\mathrm{E}\left(1 \mathrm{mg} \mathrm{ml}^{-1}\right.$; Sigma). The plugs were washed twice at room temperature in SET without pronase $\mathrm{E}$ and stored at $4{ }^{\circ} \mathrm{C}$. Immediately prior to use the plugs were washed three times in TE buffer, incubated with preboiled ribonuclease $\mathrm{A}\left(1 \mu \mathrm{g} \mathrm{ml}^{-1}\right.$; Sigma) at $37^{\circ} \mathrm{C}$ for $30 \mathrm{~min}$ in the appropriate restriction buffer for the endonuclease (New England Biolabs), and washed twice with the same buffer. For restriction endonuclease digestion, plugs containing chromosomal DNA were equilibrated with the appropriate buffer, melted at $65^{\circ} \mathrm{C}$, and digested with between 5 and $20 \mathrm{U}$ enzyme (New England Biolabs) overnight at $37^{\circ} \mathrm{C}$. The reaction was terminated by the addition of stop buffer ( $20 \mathrm{mM}$ Tris/acetate, $\mathrm{pH} 7 \cdot 5 ; 0.5 \mathrm{mM}$ EDTA $; 1 \mu \mathrm{g}$ Orange-G marker dye $\mathrm{ml}^{-1} ; 1 \%, \mathrm{w} / \mathrm{v}$, Sea-Plaque agarose) and heating to $65^{\circ} \mathrm{C}$. Samples were either stored at $-20^{\circ} \mathrm{C}$ or loaded directly onto gels.

Separation of the digested chromosomal DNA samples by PFGE was carried out with a Pharmacia-LKB 'Pulsaphor' apparatus. Electrophoresis was in a $1 \%(\mathrm{w} / \mathrm{v})$ agarose gel at a constant voltage of $160 \mathrm{~V}$ in $0.5 \times \mathrm{TBE}(5 \mathrm{mM}$ Tris/borate, $\mathrm{pH} 8.0 ; 0.5 \mathrm{mM}$ EDTA), giving a starting current of $80 \mathrm{~mA}$ : the electrophoresis buffer was maintained at $14{ }^{\circ} \mathrm{C}$ throughout the experiment. An interpolated program was used: 5-10 s pulses in $10 \mathrm{~h}$, followed by $10-30 \mathrm{~s}$ pulses in $8 \mathrm{~h}$ and $30-40 \mathrm{~s}$ pulses in $4 \mathrm{~h}$.

PCR, primers and nucleotide sequence analysis. Reaction components were as follows: 50 ng template (bacterial chromosomal DNA, approximately one eighth of an agarose plug, prepared as above) $\mu \mathrm{l}^{-1} ; 10 \mathrm{mM}$ Tris $/ \mathrm{HCl}, \mathrm{pH} 8 \cdot 0 ; 50 \mathrm{mM} \mathrm{KCl}$; $1.5 \mathrm{mM} \mathrm{MgCl} 2 ; 0 \cdot 1 \%(\mathrm{w} / \mathrm{v}$ ) gelatin; $200 \mu \mathrm{M}$ each of dATP, dCTP, dGTP and dTTP; the required primers at $2 \mu \mathrm{M}$, and $0.5 \mathrm{U}$ Taq polymerase (Amplitaq, Perkin Elmer) per $20 \mu \mathrm{l}$ reaction. The reactions were incubated for 30 cycles in a PHC2 programmable heatblock (Techne Instruments) for $2 \mathrm{~min}$ at $94^{\circ} \mathrm{C}, 2 \mathrm{~min}$ at $60^{\circ} \mathrm{C}$ and $3 \mathrm{~min}$ at $72^{\circ} \mathrm{C}$. After 30 cycles the reactions were incubated for a further $3 \mathrm{~min}$ at $72^{\circ} \mathrm{C}$. The primers used in this study were based on the nucleotide sequence of the galE gene of $S$. typhimurium LT2 (Houng et al., 1990) (Table 1). Primers 157 and 158 were used to amplify the entire coding region of the galE for nucleotide sequence analysis by the method of Embley (1991). The PCR products were purified from reaction components by precipitation at $37{ }^{\circ} \mathrm{C}$ with $20 \%$ $(\mathrm{w} / \mathrm{v}) \mathrm{PEG}_{8000}$ in $2.5 \mathrm{M} \mathrm{NaCl}$, and washing in $80 \%(\mathrm{v} / \mathrm{v})$ ethanol. The pellets were dried and resuspended in water $(25 \mu \mathrm{l}$ for a $100 \mu \mathrm{l}$ amplification). 'Cycle sequencing' was done using Taq polymerase and termination mixes from the 'Taquence' sequencing kit (United States Biochemical) with an appropriate primer, radiolabelled by $\mathrm{T} 4$ polynucleotide kinase with $\left[\gamma^{32} \mathrm{P}\right]$ ATP. Each sequence was determined at least once on each strand.

Nucleotide sequences of galE genes from various enterobacterial species were compared using programs from the PHYLIP package, version 3.51c (1993) distributed via FTP anonymous at 
Table 1. Synthetic oligodeoxyribonucleotide primers used in determining the nucleotide sequences of the galE genes of strains Ty2 and Ty21a

The location of the primers and the direction of primer extension, relative to the direction of transcription, are indicated with respect to the coding region of the galE gene. The letters $\mathrm{U}$ and $\mathrm{L}$ in the designation indicate whether the primer corresponds to the upper or lower strand sequence, respectively.

\begin{tabular}{|lllc|}
\hline Designation & $\begin{array}{l}\text { Direction } \\
\text { of primer } \\
\text { extension }\end{array}$ & Nucleotide sequence of primer & $\begin{array}{c}\text { Location } \\
\text { (base } \\
\text { position) }\end{array}$ \\
\hline 97 & Forward & 5' GGA AGT CAT ACC TGC GTA CAG TTG 3' & $37-60$ \\
98 & Reverse & 5' TTA ATC TGG GTA TGC CTG CGG ATG 3' & $994-1017$ \\
$99 \mathrm{U}$ & Forward & 5' GCG GCC AAC GTT AAA AAC CT' ATT 3' & $337-360$ \\
$99 \mathrm{~L}$ & Reverse & 5' AAT AAG GTT TTT AAC GTT GGC CGC 3' & $337-360$ \\
$100 \mathrm{U}$ & Forward & 5' ACC GAG GAT GGC ACC GGC GTA CGC 3' & $670-693$ \\
$100 \mathrm{~L}$ & Reverse & 5' GCG TAC GCC GGT GCC ATC CTC GGT 3' & $670-693$ \\
157 & Forward & 5' ATT ACA TGT CAC ACT TTT CGC ATC 3' & Upstream \\
158 & Reverse & 5' ATC GAT GGG ATT AAA TGG GGT CAT 3' & Downstream \\
$162 \mathrm{U}$ & Forward & 5' TTA TAA CCG AAA TTC TGC ACG ATC 3' & $191-214$ \\
$162 \mathrm{~L}$ & Reverse & $5^{\prime}$ GAT CGT GCA GAA TTT CGG TTA TAA 3' & $191-214$ \\
\hline
\end{tabular}

evolution.genetics.washington.edu (directory pub/phylip) by the author J. Felsenstein, Department of Genetics, University of Washington, Seattle, WA, USA. Programs DNADIST and DNAPARS were used to determine the genetic distance between genes and to perform parsimony analyses, respectively. Sequences were aligned manually using the program MACAw, version 2.0.0 Win16 (author Greg Schuler) from the National Center for Biotechnology Information, National Library of Medicine, Bethesda, USA.

Restriction digestion and gel electrophoresis of DNA fragments. The PCR products were purified from reaction components by precipitation at $37^{\circ} \mathrm{C}$ with $\mathrm{PEG}_{\mathbf{8 0 0 0}}$, as described above, and were digested with restriction endonucleases essentially as described by Maniatis et al. (1982) using restriction endonucleases and buffers supplied by New England Biolabs. Samples of DNA were separated on a $4 \%(\mathrm{w} / \mathrm{v})$ non-denaturing polyacrylamide gel in TBE buffer, $\mathrm{pH} 8.0$, at 50-100 mA.

Gel visualization and fragment size calculations. Following the resolution of restriction fragments by PFGE or electrophoresis in non-denaturing polyacrylamide, the gels were stained with ethidium bromide and the fragments visualized on an ultra-violet light transilluminator. Gels were photographed and the sizes of restriction fragments were calculated using an electronic gel documentation system (SW2000, UV Products). Bacteriophage $\lambda$ DNA concatemers (New England Biolabs) for PFGE and a 123 bp ladder (Gibco-BRL) for PCR products were used as references for the calculation of restriction fragment sizes in PFGE and non-denaturing PAGE, respectively.

\section{RESULTS}

\section{Restriction endonuclease digestion patterns of S. typhi genomic DNA}

Separate chromosomal DNA samples from $S$. typhi Ty2 and Ty21a were digested with six restriction endonucleases known to cut bacterial chromosomes infrequently (NbeI, NotI, SfII, SpeI, XbaI and XboI) and the resulting fragments were resolved into fingerprints by PFGE (data not shown). The SfiI, SpeI and $X b a I$ fingerprints had 22,17 and 19 bands, respectively, providing sufficient information to distinguish Ty21a from Ty2 without being too complex (Fig. 1). Fingerprints produced using $N b e \mathrm{I}, N o t \mathrm{I}$ and $X b o \mathrm{I}$ contained too many bands for all the individual fragments to be clearly resolved. Two additional bands (of 137 and $108 \mathrm{kbp}$ ) distinguished the Sfil fingerprint of strain Ty21a from that of Ty2, whilst the absence of two fragments (of 380 and $106 \mathrm{kbp}$ ) from the SpeI fingerprint of strain Ty21a similarly differentiated the vaccine and wild-type strains. The SpeI fingerprint of strain Ty21a included an additional fragment of more than $460 \mathrm{kbp}$, which was consistent with the loss of at least one $S p e I$ restriction site during the isolation of the vaccine strain. The differences between the $X b a$ I-digest patterns of the two strains were more complex but still permitted the discrimination between mutant S. typhi Ty21a and the wild-type strain Ty2. The sizes of the restriction fragments obtained by digesting $S$. typhi with $S f i \mathrm{I}, S p e \mathrm{I}$ and $X b a \mathrm{I}$ are given in Table 2 . The total size of the $S$. typhi chromosome could not be calculated accurately from these fingerprints, as some restriction fragments were not resolved by the PFGE conditions used in this study.

To determine the extent to which PFGE fingerprints could be used to differentiate the vaccine strain from other bacteria, the restriction pattern of XbaI-digested genomic DNA from strain Ty21a was compared with similar patterns obtained using genomic DNA from seven other enterobacterial species (Fig. 2). Each strain produced a characteristic pattern of fragments that distinguished it from S. typbi Ty21a. The XbaI fingerprint of S. typhimurium LT2 was consistent with the published physical map of its genome (Liu \& Sanderson, 1992; Liu et al., 1993). 

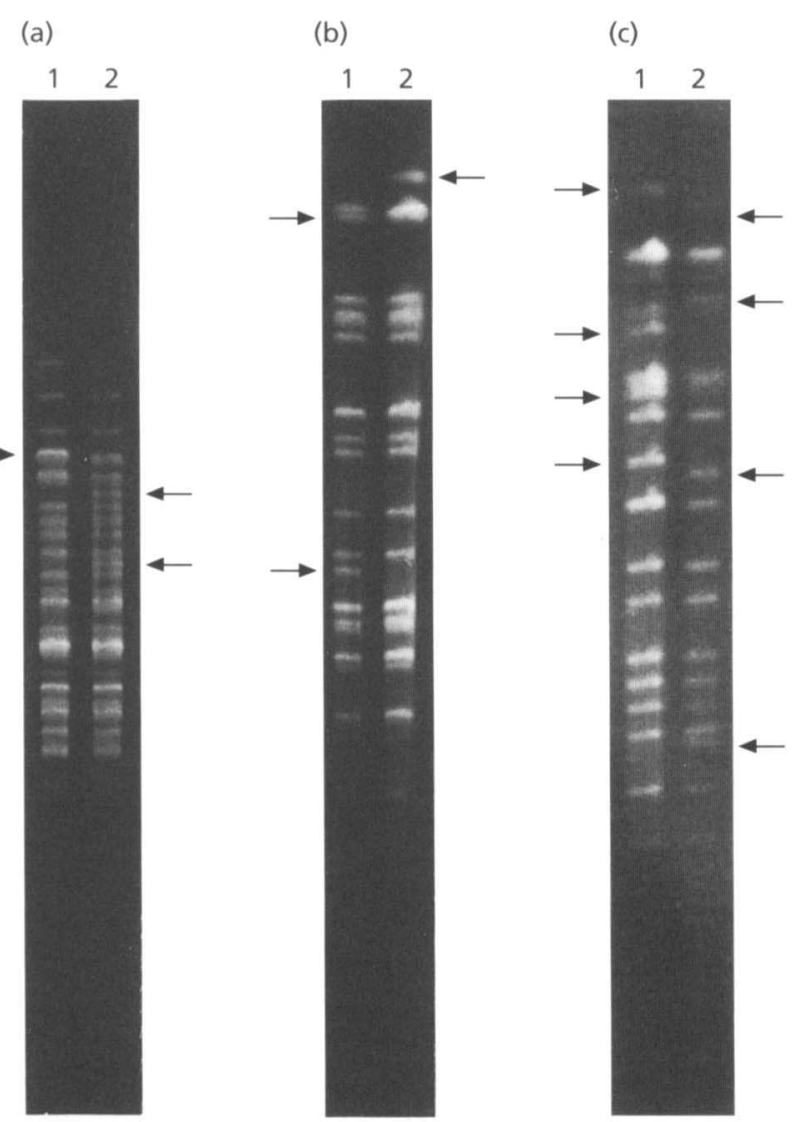

Fig. 1. Comparison of the chromosomes of S. typhi Ty2 and the mutant Ty21a by PFGE. PFGE patterns of genomic DNA from $S$. typhi strains Ty2 and Ty21a (lanes 1 and 2, respectively) digested with (a) Sfil, (b) Spel and (c) Xbal are shown. Differences between PFGE patterns are indicated by arrows.

The stability of the restriction endonuclease fingerprints obtained was investigated by passaging an isolate of S. typhi Ty21a ten times (approximately 80 generations) in $\mathrm{BHI}$ and comparing the restriction patterns obtained from the genomic DNA of cells at each passage. There were no changes between the PFGE fingerprints. To determine the stability of the restriction patterns between batches of $S$. typhi Ty21a vaccine, genomic DNA was prepared from cells cultured from five different batches of the enteric-coated formulation of the vaccine and restriction fragments were resolved by PFGE. Once again, no differences were observed between the PFGE fingerprints obtained.

\section{Nucleotide sequence analysis of the galE gene}

Oligodeoxyribonucleotide primers 157 and 158 (Table 1) were used to amplify the coding region of the galE genes of the $S$. typhi strains Ty2 and Ty21a, and the nucleotide sequences of these genes were determined completely on both DNA strands (Fig. 3). Alignment of these sequences revealed that the galE gene in the Ty21a mutant differed from that of Ty2 in two bases. The first base change was
Table 2. Sizes of restriction fragments from S. typhi resolved by PFGE following the digestion of chromosomal DNA with restriction endonucleases Sfil, Spel and $X$ bal

The sizes of the fragments resolved under the PFGE conditions (see Methods) employed in this study were calculated by the SW2000 software package (UV Products) and are given in kbp.

\begin{tabular}{|c|c|c|c|c|c|}
\hline \multicolumn{2}{|c|}{ SfiI } & \multicolumn{2}{|c|}{ SpeI } & \multicolumn{2}{|c|}{$X b a I$} \\
\hline Ty2 & Ty21a & Ty2 & Ty21a & Ty2 & Ty21a \\
\hline $222 \cdot 1$ & $220 \cdot 5$ & & $475 \cdot 5$ & $407 \cdot 1$ & \\
\hline $195 \cdot 7$ & $194 \cdot 3$ & 388.7 & & & $383 \cdot 2$ \\
\hline $172 \cdot 5$ & $170 \cdot 0$ & $378 \cdot 0$ & $378 \cdot 0$ & $320 \cdot 4$ & $322 \cdot 6$ \\
\hline $161 \cdot 8$ & & $281 \cdot 1$ & $277 \cdot 1$ & $306 \cdot 1$ & $308 \cdot 3$ \\
\hline $159 \cdot 3$ & $154 \cdot 9$ & $263 \cdot 3$ & $261 \cdot 4$ & & $278 \cdot 9$ \\
\hline \multirow[t]{2}{*}{$146 \cdot 7$} & $144 \cdot 7$ & $244 \cdot 6$ & $242 \cdot 8$ & $263 \cdot 2$ & $263 \cdot 8$ \\
\hline & $137 \cdot 4$ & $184 \cdot 3$ & $184 \cdot 4$ & $248 \cdot 2$ & \\
\hline $133 \cdot 1$ & $131 \cdot 4$ & $167 \cdot 6$ & $166 \cdot 3$ & $211 \cdot 9$ & $211 \cdot 9$ \\
\hline $126 \cdot 4$ & $126 \cdot 4$ & $159 \cdot 3$ & $158 \cdot 2$ & $208 \cdot 9$ & $208 \cdot 9$ \\
\hline $121 \cdot 5$ & $119 \cdot 9$ & $129 \cdot 7$ & $129 \cdot 7$ & $205 \cdot 0$ & \\
\hline \multirow[t]{2}{*}{113.4} & $112 \cdot 6$ & $113 \cdot 4$ & $112 \cdot 6$ & $186 \cdot 7$ & $187 \cdot 9$ \\
\hline & $108 \cdot 4$ & $106 \cdot 7$ & & $159 \cdot 6$ & \\
\hline $105^{\circ} 0$ & $104 \cdot 2$ & $90 \cdot 8$ & $91 \cdot 7$ & & 153.5 \\
\hline $98 \cdot 0$ & $97 \cdot 0$ & $82 \cdot 6$ & 83.5 & $139 \cdot 9$ & $139 \cdot 8$ \\
\hline 93.6 & $91 \cdot 7$ & $68 \cdot 6$ & $69 \cdot 4$ & $115 \cdot 7$ & 116.5 \\
\hline $79 \cdot 9$ & $79 \cdot 0$ & $47 \cdot 4$ & $47 \cdot 4$ & 101.5 & $103 \cdot 2$ \\
\hline 73.7 & $72 \cdot 9$ & $41 \cdot 6$ & $41 \cdot 6$ & 78.7 & $79 \cdot 6$ \\
\hline $62 \cdot 1$ & $60 \cdot 5$ & $32 \cdot 0$ & $32 \cdot 0$ & 68.9 & $69 \cdot 8$ \\
\hline $56 \cdot 8$ & $55 \cdot 4$ & $28 \cdot 1$ & $28 \cdot 1$ & $59 \cdot 2$ & $60 \cdot 7$ \\
\hline $45 \cdot 6$ & $47 \cdot 4$ & & & $50 \cdot 0$ & $51 \cdot 9$ \\
\hline $42 \cdot 7$ & $41 \cdot 6$ & & & & $49 \cdot 4$ \\
\hline 37.5 & 36.9 & & & 35.9 & 36.9 \\
\hline $30 \cdot 4$ & $30 \cdot 4$ & & & $26 \cdot 5$ & $27 \cdot 2$ \\
\hline $2055 \cdot 7$ & $2117 \cdot 0$ & $2807 \cdot 8$ & $2779 \cdot 7$ & $2786 \cdot 3$ & $3054 \cdot 0$ \\
\hline
\end{tabular}

a thymidine-to-cytosine transition at base position 367 , resulting in the substitution of a proline for a serine in the deduced amino acid sequence of $\mathrm{GalE}$ and the elimination of one of the two $A l u \mathrm{I}$ restriction sites in the galE gene. The second base change was the deletion of a cytosine residue between base positions 441 and 444 that shifted the reading frame bringing an opal stop codon (base position 461) in-frame. As a consequence, the deduced amino acid sequence of GalE from strain Ty21a is truncated at 153 amino acid residues.

\section{Comparison of enterobacterial galE genes}

Previous work had shown that the restriction maps of the galE genes cloned from S. typhi Ty2 and S. typhimurium LT2 were very similar (Houng et al., 1990). This was confirmed by comparison of the nucleotide sequences determined in the present study with previously published sequences of the galE genes from the enterobacterial species S. typhimurium LT2 (Houng et al., 1990), Escherichia 


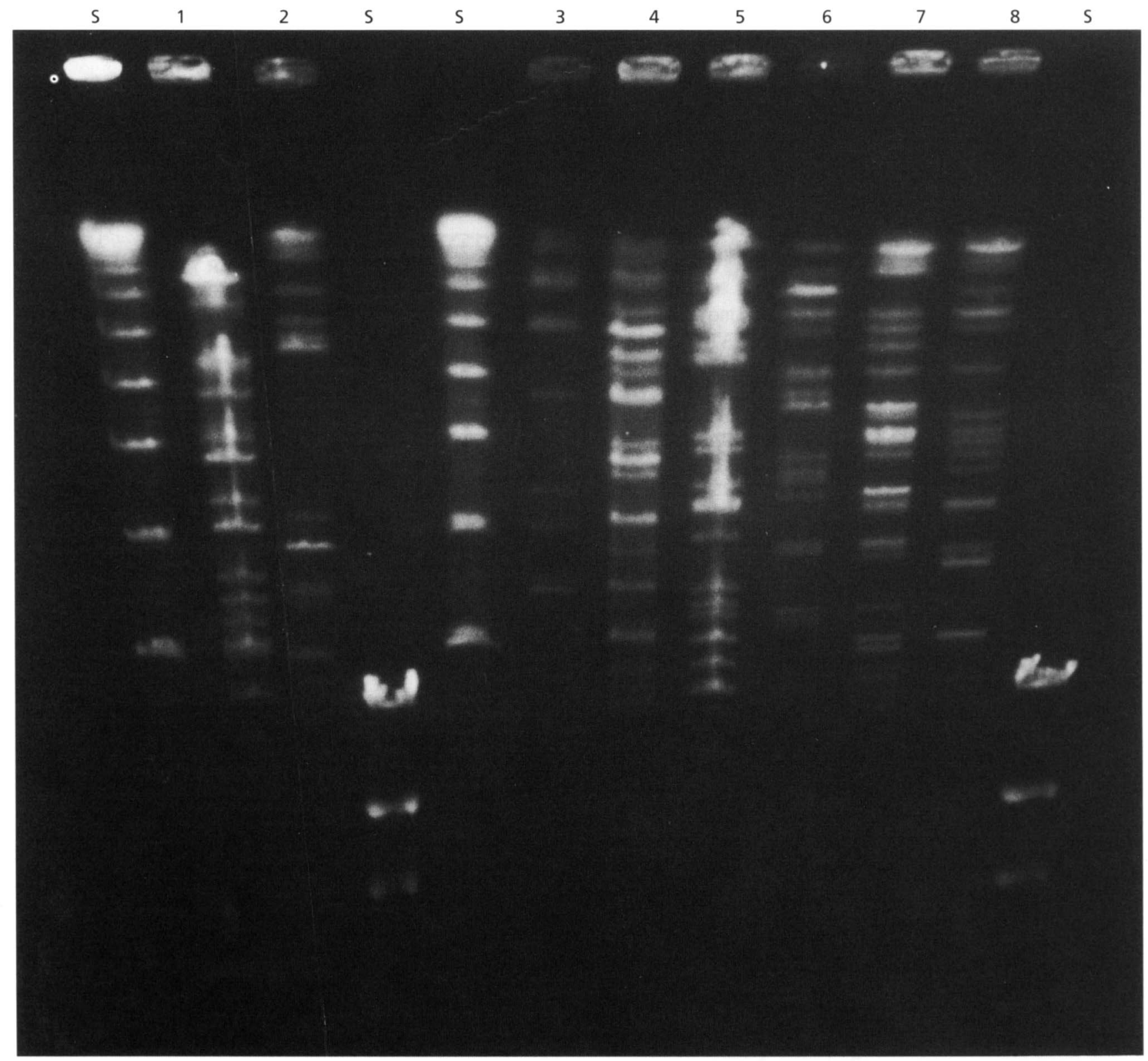

Fig. 2. PFGE patterns for S. typhi Ty21a are distinct from those of other enteric bacteria. PFGE patterns of $X$ bal-digested genomic DNA from enteric bacteria are as follows. Lanes: 1, S. typhi Ty21a; 2, S. typhimurium LT2; 3, Salmonella dublin; 4, E. coli K1; 5, E. coli K12; 6, Enterobacter cloacae; 7, Klebsiella aerogenes; 8, Klebsiella pneumoniae. The first and third lanes marked $S$ are $\lambda$ concatemer molecular size markers and the second and fourth lanes marked $S$ contain $\lambda$ DNA digested with HindIII.

coli K12 (Lemaire \& Mueller-Hill, 1986) and Erwinia amylovora (Metzger et al., 1994). The genetic distances between these galE genes, calculated by the program DNADIST using a sequence alignn generated manually using the program MACAw, are siown in Table 3. The genes from $S$. typhi Ty2 and $S$. typhimurium LT2 were the most similar to one another and both were about the same genetic distance from $E$. coli $\mathrm{K} 12$. The same relationships were observed when these nucleotide sequences were subjected to a parsimony analysis with the program DNAPARS (data not shown).
The GalE proteins of $S$. typhi and E. coli had 338 amino acids, whereas those from S. typhimurium and Erw. amylovora had 337 residues because of the deletion of different codons near the 3 '-terminus of the gene. The calculated $M_{\mathrm{r}}$ of GalE from $S$. typhi Ty 2 was 37110 . The galE gene of strain Ty2 differed from that of strain LT2 by 17 nucleotides, giving rise to six amino acid changes: (i) a glutamate substituted for an asparagine at amino acid position 88; (ii) a lysine for an arginine at position 92 ; (iii) a threonine for an alanine at position 144 ; (iv) a tyrosine for a threonine at position $149 ;(v)$ a serine for a proline at 
Primer 97

ATGAGAGTATTGGTTACAGGTGGTAGCGGTTACATTGGAAGTCATACCTGCGTACAATTG

60

$\begin{array}{lllllllllllllllllllll}\text { Ty2 } & M & R & V & I & V & T & G & G & S & G & Y & I & G & S & H & T & C & V & Q & I\end{array}$

$\begin{array}{lllllllllllllllllllll}\text { Ty21a } & M & R & V & I & V & T & G & G & S & G & Y & I & G & S & H & T & C & V & Q & L\end{array}$

CTGCAAAATGGTCATGACGTCGTCATCCTCGATAACCTCTGCAACAGCAAGCGCAGCGTG

$\begin{array}{lllllllllllllllllllll}\text { Ty2 } & I & Q & N & G & H & D & V & V & I & I & D & N & L & C & N & S & K & R & S & V\end{array}$

$\begin{array}{llllllllllllllllllllll}\text { Ty21a } & I & Q & N & G & H & D & V & V & I & I & D & N & L & C & N & S & K & R & S & V\end{array}$

CTGCCCGTTATTGAACGTCTGGGCGGTAAGCACCCGACCTTTGTCGAAGGCGATATTCGC

$\begin{array}{lllllllllllllllllllll}\text { Ty2 } & \text { I } & \mathbf{P} & \mathbf{V} & \mathbf{I} & \mathbf{E} & \mathbf{R} & \mathbf{L} & \mathbf{G} & \mathbf{G} & \mathbf{K} & \mathbf{H} & \mathbf{P} & \mathbf{T} & \mathbf{F} & \mathbf{V} & \mathbf{E} & \mathbf{G} & \mathbf{D} & \mathbf{I} & \mathbf{R}\end{array}$ $\begin{array}{llllllllllllllllllllll}\text { Ty21a } & \text { I } & \mathbf{P} & \mathbf{V} & \mathbf{I} & \mathbf{E} & \mathbf{R} & \mathrm{I} & \mathbf{G} & \mathbf{G} & \mathbf{K} & \mathbf{H} & \mathbf{P} & \mathbf{T} & \mathbf{F} & \mathbf{V} & \mathbf{E} & \mathbf{G} & \mathbf{D} & \mathbf{I} & \mathbf{R}\end{array}$ Primer162

AACGAAGCGCTTATAACCGAAATTCTGCACGATCACGCGATTGATACCGTGATTCACTTT

$\begin{array}{lllllllllllllllllllll}\text { Ty2 } & \text { N } & \text { E } & \text { A } & \text { L } & \text { I } & \text { T } & \text { E } & \text { I } & \text { I } & \text { H } & \text { D } & \text { H } & \text { A } & \text { I } & \text { D } & \text { T } & \text { V } & \text { I } & \text { H } & \text { F }\end{array}$

$\begin{array}{lllllllllllllllllllll}\text { Ty21a } & \text { N } & \text { E } & \text { A } & \text { L } & \text { I } & \text { T } & \text { E } & \text { I } & \text { L } & \text { H } & \text { D } & \text { H } & \text { A } & \text { I } & \text { D } & \text { T } & \text { V } & \text { I } & \text { H } & \text { F }\end{array}$

GCCGGCCTGAAAGCCGTCGGGAATCGGTCGCCAAGCCGCTGGAGTACTATGACAACAAC

$\begin{array}{lllllllllllllllllllll}\text { Ty2 } & A & G & \text { I } & K & \text { A } & \text { V } & \text { G } & \text { E } & \text { S } & \text { V } & \text { A } & \text { K } & \text { P } & \text { I } & \text { E } & Y & Y & D & N & N\end{array}$

$\begin{array}{lllllllllllllllllllll}\text { Ty21a } & A & G & \text { I } & K & A & V & G & E & S & V & A & K & P & I & E & Y & Y & D & N & N\end{array}$

Primer 99

GTCAACGGTACGCTGCGGTTGGTCAGCGCCATGCGTGCGGCCAACGTTAAAAACCTTATT

$\begin{array}{lllllllllllllllllllll}\text { Ty2 } & V & N & G & T & L & R & L & V & S & A & M & R & A & A & N & V & K & N & I & I\end{array}$

$\begin{array}{lllllllllllllllllllll}\text { Ty21a } & V & N & G & T & I & R & L & V & S & A & M & R & A & A & N & V & K & N & I & I\end{array}$

AluI

C

TTTAGCTCCTCTGCCACCGTTTATGGCGATCAGCCCAAAATTCCTTACGTCGAAAGTTTT

420

$\begin{array}{lllllllllllllllllllll}\text { Ty2 } & F & S & S & S & A & T & V & Y & G & D & Q & P & K & I & P & Y & V & E & S & F\end{array}$

$\begin{array}{lllllllllllllllllllll}\text { Ty21a } & F & S & P & S & A & T & V & Y & G & D & Q & P & K & I & P & Y & V & E & S & F\end{array}$

CCTACCGGCACGCCGCAAAGCCCCTACGGCAAAAGTAAATTGATGGTAGAACAGATCCTC

480

$\begin{array}{lllllllllllllllllllll}\text { Ty2 } & \mathbf{P} & \mathbf{T} & \mathbf{G} & \mathbf{T} & \mathbf{P} & \mathbf{Q} & \mathbf{S} & \mathbf{P} & \mathbf{Y} & \mathbf{G} & \boldsymbol{K} & \mathbf{S} & \boldsymbol{K} & \mathbf{L} & \mathbf{M} & \mathbf{V} & \mathbf{E} & \boldsymbol{Q} & \mathbf{I} & \mathbf{L}\end{array}$

$\begin{array}{lllllllllllllll}T y 21 a & P & T & G & T & P & Q & S & P & T & A & K & V & N & \text { End }\end{array}$

ACCGATCTGCAAAAAGCCCAGCCGGAGTGGAGTATTGCGCTGCTGCGTTATTTCAATCCG

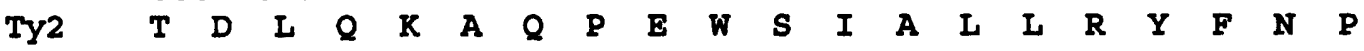

GTCGGCGCGCACCCGTCGGGCGACATGGGAGAAGATCCGCAAGGTATTCCGAATAACCTG

$\begin{array}{lllllllllllllllllllll}\text { Ty2 } & \text { V } & \text { G } & \text { A } & \text { H } & \text { P } & \text { S } & \text { G } & \text { D } & \text { M } & \text { G } & \text { E } & \text { D } & \text { P } & \text { Q } & \text { G } & \text { I } & \text { P } & \text { N } & \text { N } & \text { L }\end{array}$

ATGCCCTATATCGCCCAGGTCGCCGTGGGTCGTCGCGAATCGCTCGCCGTTTTCGGCAAC

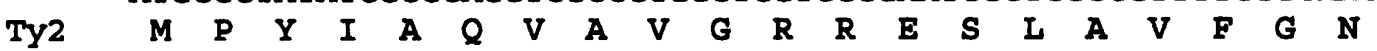
Primer 100

GATTACCCGACCGAGGATGGCACCGGCGTACGCGATTACATTCACGTTATGGACTTAGCC

300

360

240

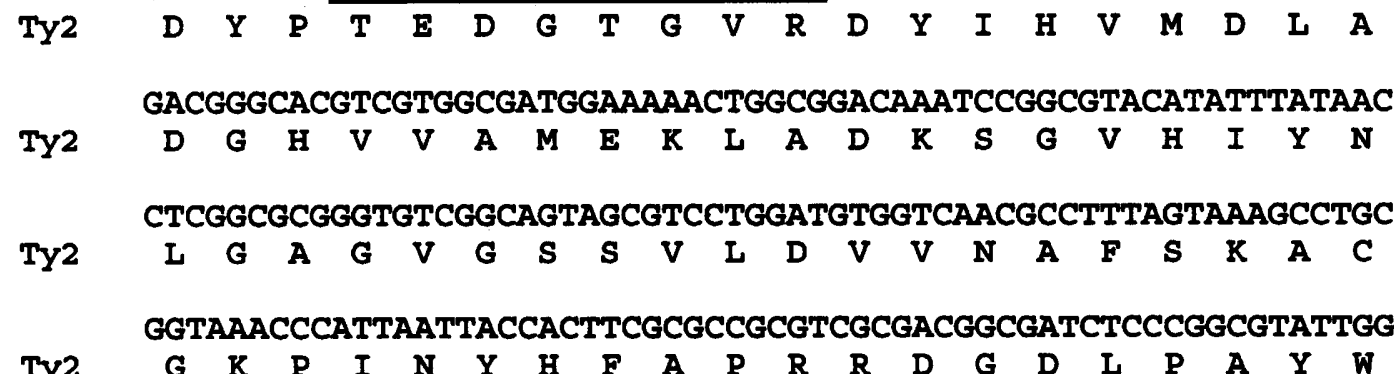

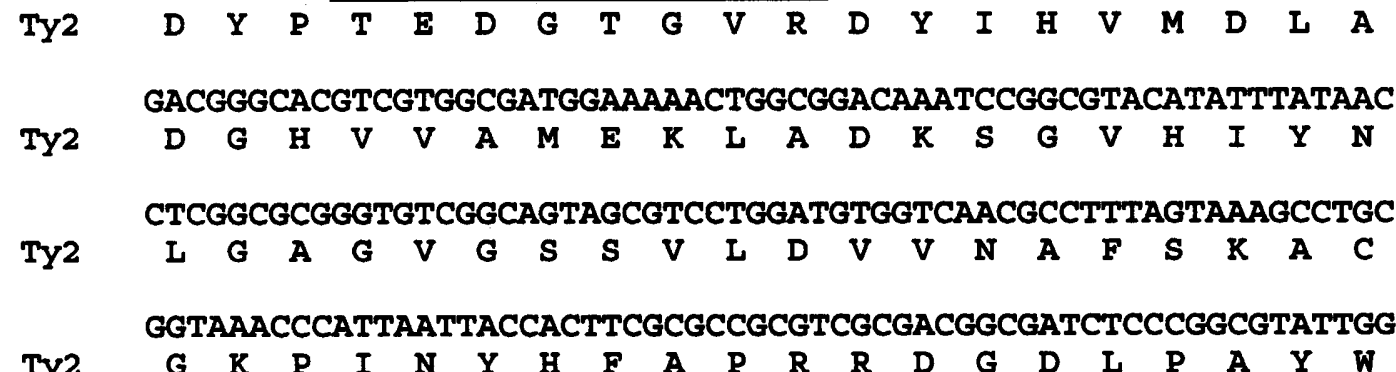

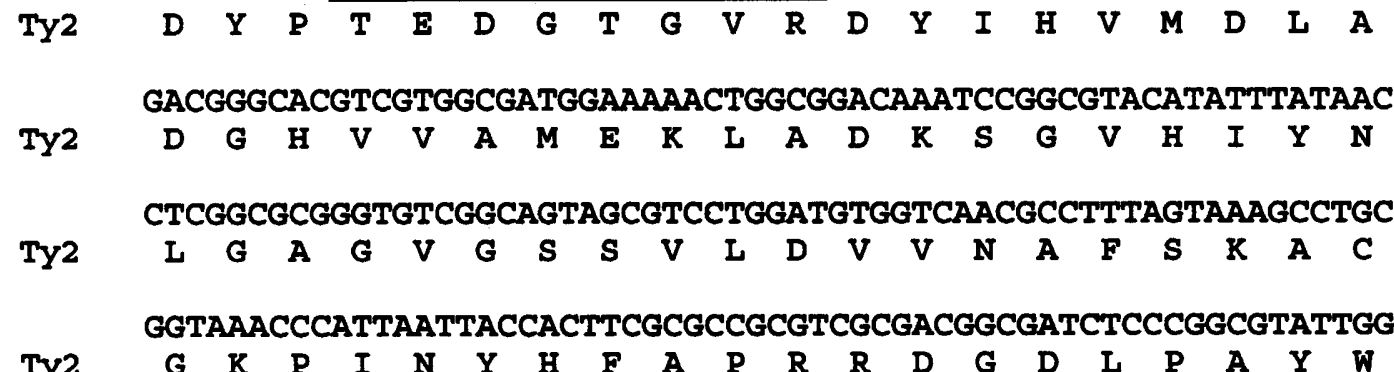

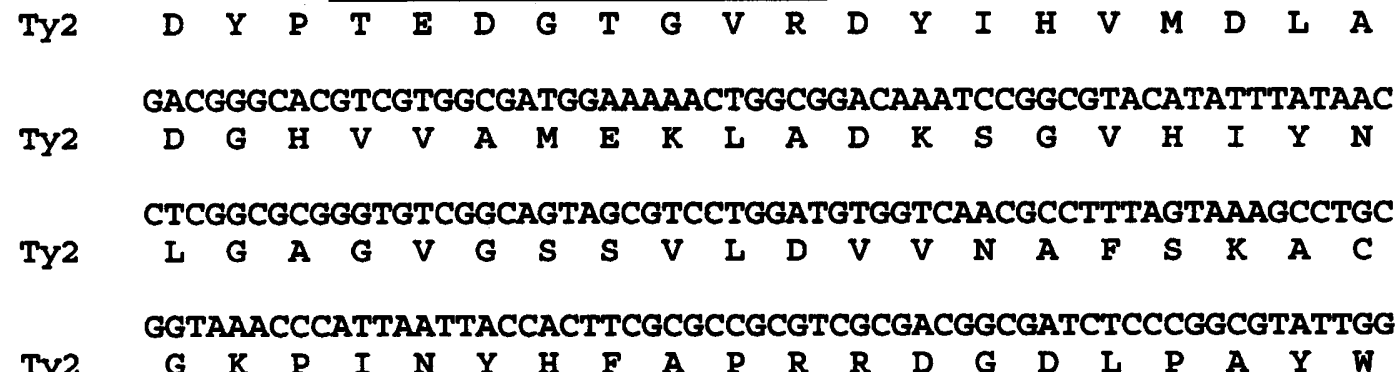

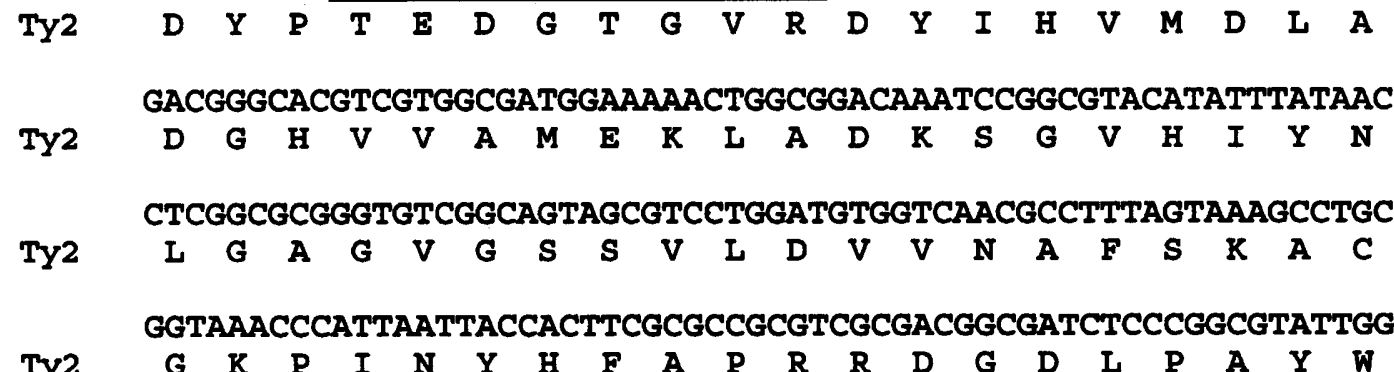

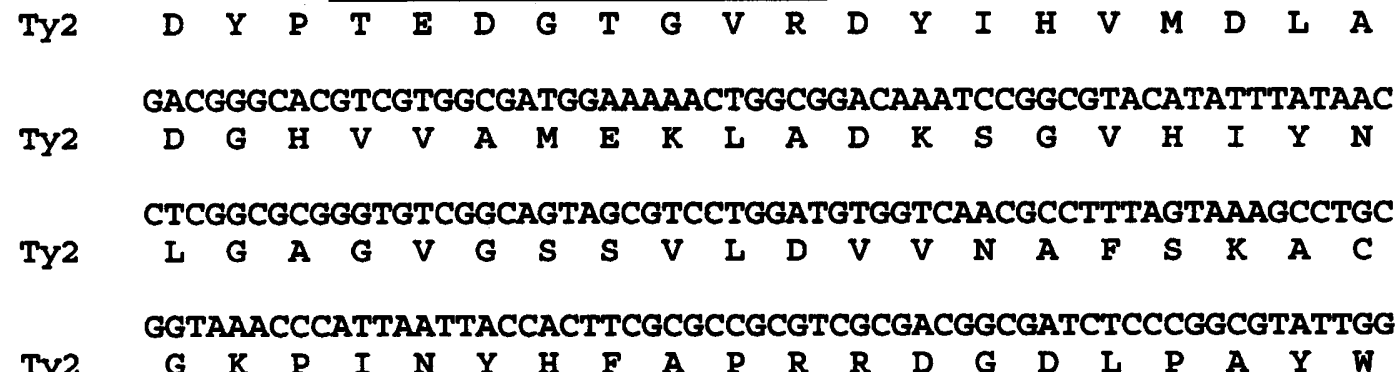

540

600

660

720

780

840

900

$$
\text { AluI }
$$

GCGGATGCCAGCAAAGCCGATCGCGAGCTGAACTGGCGCGTCACCCGCACGCTTGACGAA

960

$\begin{array}{lllllllllllllllllllll}\text { Ty2 } & A & \mathbf{D} & \mathbf{A} & \mathbf{S} & \mathrm{K} & \mathbf{A} & \mathbf{D} & \mathbf{R} & \mathbf{E} & \mathrm{L} & \mathbf{N} & \mathbf{W} & \mathbf{R} & \mathbf{V} & \mathbf{T} & \mathbf{R} & \mathbf{T} & \mathbf{L} & \mathbf{D} & \mathbf{E}\end{array}$ Primer 98

ATGGCGCAGGACACTTGGCACTGGCAGTCACGCCATCCGCAGGCATACTCAGATTAA

$\begin{array}{llllllllllllllllllll}\text { Ty2 } & M & A & Q & D & T & W & H & W & Q & S & R & H & P & Q & A & Y & S & D & \text { End }\end{array}$ 
Table 3. Matrix of the genetic distances between the galE genes of enteric bacteria

The genetic distances were calculated using the DNADIST program from the PHYLIP package.

\begin{tabular}{|lccccc|}
\hline & S. typhi Ty2 & S. typhi Ty21a & E. coli K12 & S. typhimurium & Erw. \\
LT2 & & & \\
amylovora
\end{tabular}

position 337; and (vi) an additional arginine inserted at position 291. The GalE proteins of both Salmonella species were also similar to the corresponding protein of E. coli, with the majority of amino acid mismatches occurring at the carboxy terminus. The GalE sequence of S. typhimurium LT2 had three additional amino acid changes (positions 88, 92 and 144) from that of E. coli which were not present in $S$. typhi Ty2.

\section{Detection of the mutant galE gene}

The change in the $A l u I$ restriction site at position 424 was used as a rapid test to distinguish between the galE genes of strains Ty2 and Ty21a (Fig. 4). Digestion of the PCRamplified galE gene from strain Ty2 with $A l u \mathrm{I}$ resulted in three fragments of 562, 388 and 119 bp (Fig. 4, lane 3), whereas the equivalent PCR product from strain Ty21a digested with $A l u \mathrm{I}$ resulted in fragments of 950 and 119 bp (Fig. 4, lane 2).

\section{DISCUSSION}

Molecular techniques provide rapid methods for the detailed analysis of bacterial chromosomes and genes. With the advent of vaccines developed by genetical means, quality control tests based on genetical analyses are necessary. In the present study the techniques of PFGE and PCR-based nucleotide sequencing are used to characterize the oral typhoid vaccine strain Ty21a at the level of the whole genome and of the individual gene, respectively.

Genotypic analyses, by the resolution of restriction fragments of genomic DNA upon PFGE, permitted the direct identification of mutations in the Ty21 a vaccine strain. The resulting restriction patterns were characteristic for the vaccine strain and provided information on the physical structure of the chromosome. It was possible to compare the fingerprints from different batches of vaccine and seed lots used in vaccine production. Thus, the generation of genomic restriction patterns by PFGE provided a comparatively simple and reliable means of confirming the identity and genetical stability of an attenuated strain. Since the differences between genomic restriction fragment patterns of strains Ty2 and Ty21a represented only those nucleotide base changes that either created or eliminated particular restriction sites, PFGE identified a small proportion of the mutational changes in the vaccine strain. That differences between restriction patterns were discerned implied that there were a considerable number of mutations in the attenuated strain.

Direct nucleotide sequence analysis identified the mutations generated in the galE gene during the isolation of strain Ty21a. These mutations were consistent with NTG mutagenesis which usually induced transitions but occasionally gave rise to small deletions (Drake \& Baltz, 1976). Comparison of the nucleotide sequences of the galE genes from both $S$. typhi strains Ty2 and Ty21a revealed that there were two mutations in the galE gene of strain Ty21a. The galE phenotype of strain Ty21a was attributable to the frameshift resulting from the deletion of one of a run of four cytosine residues between base positions 441 and 444 (Fig. 3) and was consistent with the published observation that single base frameshifts frequently occur within monotonous runs of identical bases (Ripley et al., 1986). This mutation resulted in the expression of a truncated UDPgalactose 4-epimerase and explained the reported stability of the galE mutation in strain Ty21a (Germanier \& Furer, 1975, 1983), since a frameshift would be less amenable to reversion or suppression than mutations caused by single base changes. It was unknown whether the base transition $(T \rightarrow C$ base position 367 ; Fig. 3 ) in the vaccine strain would cause the galE phenotype and contribute to its stability. Comparison of the nucleotide sequences of the galE genes of the S. typhi strains with those of other enterobacterial species confirmed the reported similarity (Houng et al., 1990) between the galE genes of E. coli and Salmonella species (Table 3).

Fig. 3. Nucleotide and deduced amino acid sequences of the galE genes of S. typhi strains Ty2 and Ty21a. The complete nucleotide sequence of the galE gene of strain Ty2 is shown with the base changes found in the corresponding gene of strain Ty21a indicated above ( $\Delta$ represents the deletion of a single base). The deduced amino acid sequences are shown below the nucleotide sequences. Sequences corresponding to the primers, listed in Table 1, are underlined. 


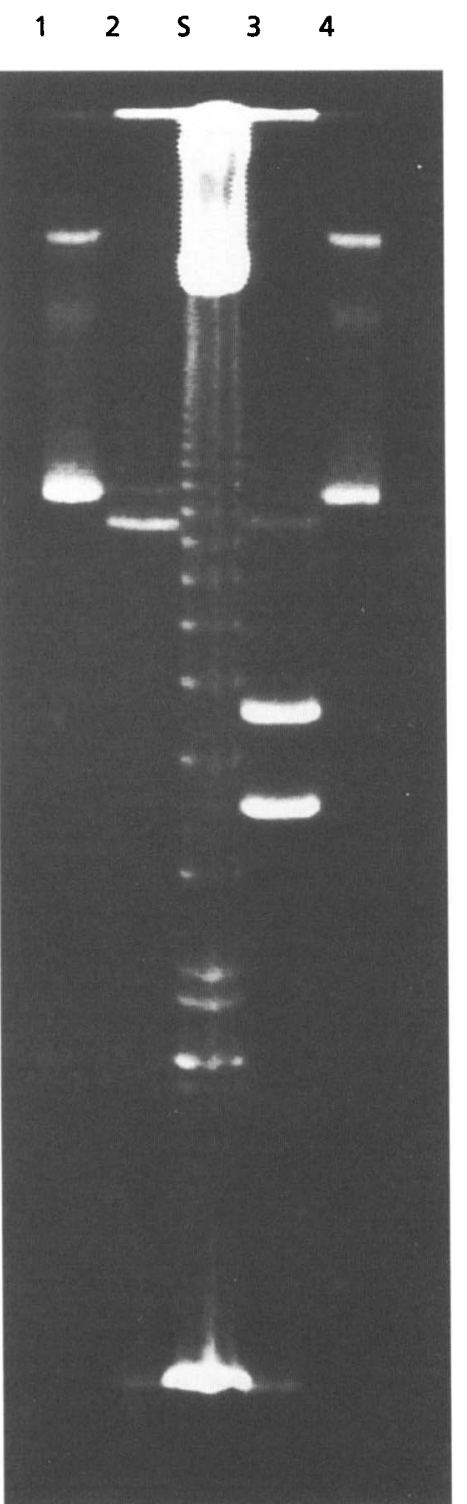

Fig. 4. Digestion of the PCR-amplified galE gene with Alul distinguishes $S$. typhi Ty2 from strain Ty21a. The galE genes of strain Ty21a and Ty2 were amplified by the PCR using primers 157 and 158, digested with Alul, and resolved on a $4 \%$ nondenaturing polyacrylamide gel. Lanes: 1 and 2, the PCR product of strain Ty21a uncut and cut with Alul, respectively; 3 and 4, the PCR product of strain Ty2 cut with Alul and uncut, respectively; S, a 123 bp size marker.

The data obtained in the present study show that molecular genetical techniques such as PFGE and PCR can be applied in the quality control of oral typhoid vaccine and have potential for use in the quality control programmes for other live attenuated bacterial vaccines. These approaches are precise and rapid, as well as being reasonably inexpensive. Existing procedures for the quality control of the $S$. typhi Ty21a vaccine, which are intended to demonstrate whether the strain in a particular vaccine batch is identical to that previously shown to be safe in clinical trials, are based exclusively on the phenotypic characterization of the strain isolated from the batch of vaccine under examination. Following the chemical mutagenesis of strain Ty2, the galE mutation was not reintroduced into Ty2 to ensure that the vaccine strain was isogenic, consequently Ty21a possesses numerous additional mutations many of which are not exhibited as easily detectable phenotypic traits. Currently, identity tests for this vaccine confirm the presence of the mutations that result in easily detectable alterations in the biochemical and antigenic characteristics of the strain, such as the galE phenotype, the failure to produce $\mathrm{H}_{2} \mathrm{~S}$, or the inability to synthesize the polysaccharide Vi antigen. These characteristics are not necessarily responsible for the attenuation of the strain, their detection depends on phenotypic expression, and they represent only a small proportion of the genome. Consequently, they cannot be used to assess the safety of the strain, they are poor indicators of the identity of the Ty21a strain, and cannot be used to assess its genetical stability.

Although it has been shown in volunteer studies with isogenic galE derivatives of strain Ty2 that galE is not the mutation responsible for attenuation (Hone et al., 1988), the galE phenotype is used as a marker for the identification of strain Ty21a in the current quality control procedures for this vaccine. The base transition at position 427 (Fig. 3) that eliminated an $A l u \mathrm{I}$ restriction site in the vaccine strain provided an alternative, genotypic test for the identification of the vaccine strain. This was conveniently demonstrated by the $A l u \mathrm{I}$ digestion of the PCRamplified galE gene. It had distinct advantages over the existing tests for galE, which involve biochemical assays and growth on differential culture media; it was not dependent upon the phenotypic expression of galE and, since it was based on PCR, could be performed directly on vaccine samples without requiring further subculture.

The molecular genetical approach described in the present study can be applied to the quality control testing of other live bacterial vaccines. Although the use of $B C G$ vaccine is long established, the vaccine strains are relatively poorly characterized and their identity is assumed from their slow growth and the microscopic examination of acid-fast stained smears. Data from PFGE and PCR-based methods would enhance the existing identification of BCG vaccine strains used by different manufacturers and permit analysis of the genetical stability of the strains between batches. In addition to existing live vaccines, strains of $S$. typhi with mutations in the genes encoding enzymes of the pre-chorismate metabolic pathway (such as $\operatorname{aro} A, \operatorname{aro} C$ and $\operatorname{aroD}$ ) and strains of Vibrio cholerae lacking the $\operatorname{ctx} A$ gene (but resistant to $\mathrm{Hg}^{++}$) have both been shown to be attenuated and immunogenic in human volunteers (Dougan et al., 1990; Levine \& Kaper, 1993; Dougan, 1994). The direct examination of the genome, utilizing both PFGE fingerprinting and PCR-based methods for the detection of their respective attenuating lesions, will expedite the quality control of rationally designed, attenuated bacterial vaccine strains such as these when they become available. Similar methods utilizing PCR have been employed to distinguish the attenuating lesions of viral vaccine strains (Fineschi et al., 1992; Scherba et al., 1992; Mori, 1994; Takeda et al., 1994). 


\section{REFERENCES}

Ashcroft, M. T., Morrison-Ritchie, J. \& Nicholson, C. C. (1964). Controlled field trial in British Guyana school-children of heatkilled-phenolized and acetone-killed lyophilized typhoid vaccines. Am J Hyg 79, 196-206.

Black, R. E., Levine, M. M., Ferreccio, C., Clements, M. L., Lanata, C., Rooney, J., Germanier, R. \& Chilean Typhoid Committee (1990). Efficacy of one or two doses of Ty21a Salmonella typhi vaccine in enteric-coated capsules in a controlled field trial. Vaccine 8, 81-84.

Bohm, H. \& Karch, H. (1992). DNA fingerprinting of Eschericbia coli O157: H7 strains by pulsed-field gel electrophoresis. J Clin Microbiol 30, 2169-2172.

Bygraves, J. A. \& Maiden, M. C. J. (1992). Analysis of the clonal relationships between strains of Neisseria meningitidis by pulsed field gel electrophoresis. J Gen Microbiol 138, 523-531.

Cardenas, L. \& Clements, J. D. (1992). Oral immunization using live attenuated Salmonella spp. as carriers of foreign antigens. Clin Microbiol Rev 5, 328-342.

Carle, G. F., Frank, M. \& Olson, M. V. (1986). Electrophoretic separations of large DNA molecules by periodic inversion of the electric field. Science 232, 64-68.

Chatfield, S. N., Strugnell, R. A. \& Dougan, G. (1989). Live Salmonella as vaccines and carriers of foreign antigenic determinants. Vaccine 7, 495-498.

Chatfield, S. N., Charles, I. G., Makoff, A. J., Oxer, M. D., Dougan, G., Pickard, D., Slater, D. \& Fairweather, N. F. (1992). Use of the nirB promoter to direct the stable expression of heterologous antigens in Salmonella oral vaccine strains: development of a singledose oral tetanus vaccine. Biotechnology 10, 888-892.

Clements, J. D. \& El-Morshidy, S. (1984). Construction of a potential live oral bivalent vaccine for typhoid fever and choleraEscherichia coli related diarrhoea. Infect Immun 46, 564-569.

Dougan, G. (1994). The molecular basis for the virulence of bacterial pathogens: implications for oral vaccine development. Microbiology 140, 215-224.

Dougan, G., Maskell, D., Pickard, D. \& Hormaeche, C. E. (1987). Isolation of stable aro $A$ mutants of Salmonella typhi Ty2: properties and preliminary characterization in mice. Mol \& Gen Genet 207, 402-405.

Dougan, G., Hofnung, M., Lanzavecchia, A. \& Leclerc, C. (1990). Immune response to proteins with recombinant epitopes, perspectives for vaccines. In Conferences Philipe Laudat 1990 INSERM, pp. 171-220. Paris: INSERM.

Drake, J. W. \& Baltz, R. H. (1976). The biochemistry of mutagenesis. Annu Rev Biocbem 45, 11-37.

Embley, T. M. (1991). The linear PCR reaction: a simple and robust method for sequencing amplified rRNA genes. Lett Appl Microbiol 13, 171-174.

Fineschi, N., Pellegrini, V., Zuckerman, A. J. \& Cavalieri, F. (1992). Assessment of inactivation of hepatitis A vaccine by compound PCR. J Virol Methods 39, 157-163.

Formal, S. B., Baron, L. S., Kopecko, D. J., Washington, C., Powell, C. \& Life, C. A. (1981). Construction of a potential bivalent vaccine strain: introduction of Shigella sonnei form I antigen genes into the galE Salmonella typhi Ty21a typhoid vaccine strain. Infect Immun 34, 746-750.

Forrest, B. D. (1991). Oral typhoid vaccine Ty21a. Lancet 338, 1455-1456.

Forrest, B. D., LaBrooy, J. T., Beyer, L., Dearlove, C. E. \&
Shearman, D. J. (1991). The human humoral immune response to Salmonella typhi Ty21a. J Infect Dis 163, 336-345.

Germanier, R. \& Furer, E. (1975). Isolation and characterization of galE mutant Ty21a of Salmonella typhi: a candidate for a live, oral typhoid vaccine. J Infect Dis 131, 553-558.

Germanier, R. \& Furer, E. (1983). Characteristics of the attenuated oral vaccine strain S. typhi Ty21a. Dev Biol Stand 53, 3-7.

Gilman, R. H., Hornick, R. B., Woodward, W. E., DuPont, H. L., Snyder, M. J., Levine, M. M. \& Libonati, J. P. (1977). Evaluation of a UDP-glucose-4-epimeraseless mutant of Salmonella typhi as a live oral vaccine. $J$ Infect $D$ is 136, 717-723.

Hirschel, B., Wuthrich, R., Somaini, B. \& Steffen, R. (1985). Inefficacy of the commercial live oral Ty21a vaccine in the prevention of typhoid fever. Eur J Clin Microbiol 4, 295-298.

Hone, D. M., Attridge, S. R. \& Forrest, B. (1988). A galE via (Vi antigen-negative) mutant of Salmonella typhi $\mathrm{Ty} 2$ retains virulence in humans. Infect Immun 56, 1326-1333.

Hone, D. M., Harris, A. M., Chatfield, S., Dougan, G. \& Levine, M. M. (1991). Construction of genetically defined double aro mutants of Salmonella typhi. Vaccine 9, 810-816.

Houng, H. H., Kopecko, D. J. \& Baron, L. S. (1990). Molecular cloning and physical and functional characterization of the Salmonella typbimurium and Salmonella typbi galactose utilization operons. J Bacteriol 172, 4392-4398.

Lemaire, H. G. \& Mueller-Hill, B. (1986). Nucleotide sequences of the galE and the galT genes of E. coli. Nucleic Acids Res 14, 7705-7711.

Levine, M. M. \& Kaper, J. B. (1993). Live oral vaccines against cholera: an update. Vaccine 11, 207-212.

Levine, M. M., Ferreccio, C., Black, R. E., Germanier, R. \& Chilean Typhoid Committee (1987). Large-scale field trial of Ty21a live oral typhoid vaccine in enteric-coated capsule formulation. Lancet $\mathbf{i}$, 1049-1052.

Liu, S. L. \& Sanderson, K. E. (1992). A physical map of the Salmonella typhimurium LT2 genome made by using $X b a \mathrm{I}$ analysis. $J$ Bacteriol 174, 1662-1672.

Liu, S. L., Hessel, A. \& Sanderson, K. E. (1993). The $X b a I-B \ln I-C e u I$ genomic cleavage map of Salmonella typhimurium LT2 determined by double digestion, end labelling, and pulsed-field gel electrophoresis. $J$ Bacteriol 175, 4104-4120.

Maniatis, T., Fritsch, E. F. \& Sambrook, J. (1982). Molecular Cloning: a Laboratory Manual. Cold Spring Harbor, NY : Cold Spring Harbor Laboratory.

Metzger, M., Bellemann, P., Bugert, P. \& Geider, K. (1994). Genetics of galactose metabolism of Erwinia amylovora and its influence on polysaccharide-synthesis and virulence of the fire blight pathogen. J Bacteriol 176, 450-459.

Mori, T. (1994). A simple method for genetic differentiation of the AIK-C vaccine strain from wild strains of measles virus. Biologicals 22, 179-185.

Murphy, J. R., Grez, L., Schlesinger, L., Ferreccio, C., Baqar, S., Munoz, C., Wasserman, S. S., Losonsky, G., Olson, J. G. \& Levine, M. M. (1991). Immunogenicity of Salmonella typhi Ty21a vaccine for young children. Infect Immun 59, 4291-4293.

Polish Typhoid Committee (1966). Controlled field trials and laboratory studies on the effectiveness of typhoid vaccines in Poland. Bull WHO 34, 211-222.

Ripley, L. S., Clark, A. \& deBoer, J. G. (1986). Spectrum of spontaneous frameshift mutations: sequences of bacteriophage T4 rII gene frameshifts. $J$ Mol Biol 191, 601-613.

Scherba, G., Jin, L., Schnitzlein, W. M. \& Vodkin, M. H. (1992). 
Differential polymerase chain reaction for detection of wild-type and a vaccine strain of Aujeszky's disease (pseudorabies) virus. $J$ Virol Methods 38, 131-143.

Schwartz, D. C. \& Cantor, C. R. (1984). Separation of yeast chromosome-sized DNAs by pulsed field gradient gel electrophoresis. Cell 37, 67-75.

Simanjuntak, C. H., Paleologo, F. P., Punjabi, N. H., Darmowigoto, R., Soeprawoto, Totosudirjo, H., Haryanto, P., Suprijanto, E., Witham, N. D. \& Hoffman, S. L. (1991). Oral immunisation against typhoid fever in Indonesia with Ty21a vaccine. Lancet 338, 1055-1059.

Takeda, N., Sakae, K., Agboatwalla, M., Isomura, S., Hondo, R. \&
Inouye, S. (1994). Differentiation between wild and vaccine-derived strains of poliovirus by stringent microplate hybridization of PCR products. J Clin Microbiol 32, 202-204.

Wahdan, M. H., Serie, C., Cerisier, Y., Sallam, S. \& Germanier, R. (1982). A controlled field trial of live Salmonella typhi strain Ty21a oral vaccine against typhoid: three-year results. J Infect Dis 145, 292.

Yugoslav Typhoid Commission (1964). A controlled field trial of the effectiveness of acetone-dried and inactivated and heat-phenolinactivated typhoid vaccines in Yugoslavia. Bull WHO 30, 623-630.

Received 17 January 1995; revised 3 April 1995; accepted 20 April 1995. 